\title{
Reoperative laparoscopic fundoplication for the treatment of failed fundoplication
}

\author{
Pavlos K. Papasavas, MDa \\ Woodrow W. Yeaney, MD ${ }^{\mathrm{b}}$ \\ Rodney J. Landreneau, MD \\ Fernando D. Hayetian, $\mathrm{MD}^{\mathrm{a}}$ \\ Daniel J. Gagné, MDa \\ Philip F. Caushaj, MDa \\ Robin Macherey, $\mathrm{RN}^{\mathrm{b}}$ \\ Susan Bartley, $\mathrm{RN}^{\mathrm{a}}$ \\ Richard H. Maley, Jr, MD \\ Robert J. Keenan, MDa
}

From the Division of Minimally Invasive Surgery, The Western Pennsylvania Hospital, ${ }^{\mathrm{a}}$ and the Division of Thoracic Surgery, Allegheny General Hospital, Pittsburgh, Pa. $^{\text {b }}$

Supported in part by a research grant from Tyco Healthcare.

Read at the Eighty-second Annual Meeting of The American Association for Thoracic Surgery, Washington, DC, May 5-8, 2002.

Received for publication May 3, 2002; revisions requested April 7, 2004; accepted for publication April 14, 2004.

Address for reprints: Robert J. Keenan, MD, Division of Thoracic Surgery, Allegheny General Hospital, 320 E North Ave, Pittsburgh, PA 15212 (E-mail: rkeenan@ wpahs.org).

J Thorac Cardiovasc Surg 2004;128:509-16 $0022-5223 / \$ 30.00$

Copyright $\odot 2004$ by The American Association for Thoracic Surgery

doi:10.1016/j.jtcvs.2004.04.037
Objective: This study was undertaken to determine the safety and efficacy of reoperative laparoscopic fundoplication for patients with failed fundoplication.

Methods: Thirty-nine of 612 consecutive patients who had undergone fundoplication underwent laparoscopic reoperative fundoplication for recurrent symptoms, persistent dysphagia, or gas bloat. An additional 15 patients were referred from outside facilities for reoperation. Preoperative evaluation included barium swallow $(\mathrm{n}=54)$, esophagogastroduodenoscopy $(\mathrm{n}=54)$, esophageal manometry $(\mathrm{n}=34)$, and 24-hour ambulatory $\mathrm{pH}$ measurement $(\mathrm{n}=32)$. Symptom severity before and after surgery was evaluated with a visual analog scoring scale. The mean follow-up was 22.5 months.

Results: The primary symptoms that led to reoperation in the 54 patients were heartburn $(n=26)$, dysphagia $(n=23)$, and gas bloat $(n=5)$. Average time from initial operation to reoperation was 22.7 months. There were 3 conversions to open technique. An anatomic reason for the failure of the initial fundoplication was found in $69 \%$ of cases: slipped or misplaced fundoplication $(n=14)$, disrupted fundoplication $(\mathrm{n}=8)$, transdiaphragmatic herniation $(\mathrm{n}=7)$, achalasia $(\mathrm{n}=1)$, and tight fundoplication $(\mathrm{n}=7)$. Fourteen patients had 15 perioperative complications. Mean hospital stay was 2.3 days. Symptoms such as heartburn, dysphagia, and gas bloat improved significantly after reoperation; $40 \%$ to $50 \%$ of patients had scores 0 to 2 , $21 \%$ to $45 \%$ had scores 3 to 7 , and $9 \%$ to $29 \%$ had scores 8 to 10 . Proton-pump inhibitor use after operation decreased from $88 \%$ to $36 \%$. Fifty-two percent of patients completely discontinued any antireflux medications. Three patients had failure of the reoperation and required additional procedures.

Conclusion: Laparoscopic reoperation for failed fundoplication is feasible and can achieve resolution of symptoms for a significant percentage of patients.

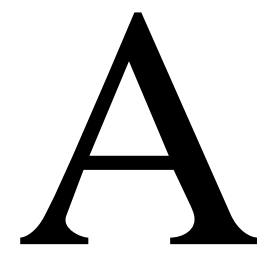

pproximately $40 \%$ of US adults have reflux symptoms at least once a month, $14 \%$ weekly, and $7 \%$ daily. ${ }^{1-3}$ Of these, about 4 in 1000 go on to have complications of gastroesophageal reflux disease (GERD), such as ulceration, stricture, or dysplasia, that mandate surgical or medical treatment. ${ }^{4}$ Long-term therapy with proton-pump inhibitors can be effective in treating severe symptoms of reflux esophagitis and its sequelae. However, $80 \%$ of patients have recurrence of severe GERD within 6 to 8 months of cessation of medical therapy. ${ }^{5}$ 


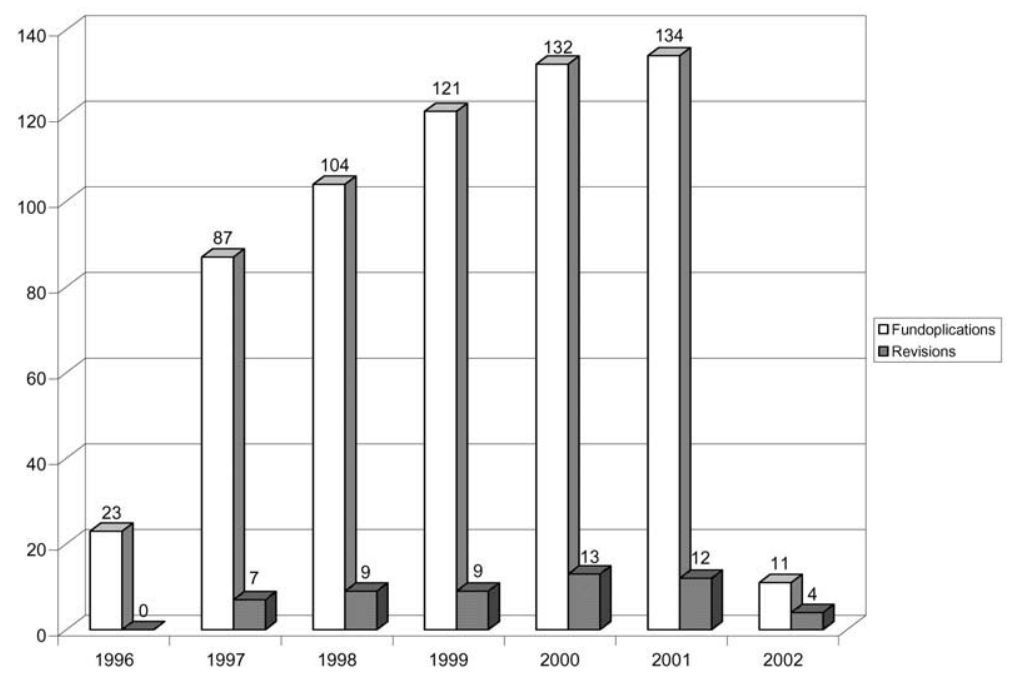

Figure 1. Time distribution of reoperations.

The number of antireflux operations increased $34 \%$ from 1997 to 1999 , and 34,800 procedures are now done annually in the United States. ${ }^{6}$ Open antireflux surgery has a $91 \%$ success rate at 10 -year follow up. ${ }^{7}$ Similarly, laparoscopic fundoplication has been shown to achieve good or excellent relief of reflux symptoms in $90 \%$ of patients at 5-year follow-up. ${ }^{8}$ Although results are excellent, revision is sometimes required. Open antireflux procedures have an approximate $10 \%$ failure rate at 10 postoperative years. ${ }^{7}$ Rates for reoperative laparoscopic antireflux surgery are comparable and range from $4 \%$ to $8 \% .^{8-14}$ There is concern that improvement of symptoms after reoperative antireflux surgery is not as good as after primary surgery, although success rates as high as $90 \%$ have been reported..$^{9,15-17}$ We investigated our experience with reoperative laparoscopic fundoplication to determine its safety and efficacy in alleviating symptoms related to GERD.

\section{Patients and Methods}

Between June 1996 and January 2002, a total of 612 consecutive patients underwent fundoplication for medically recalcitrant GERD at the West Penn Allegheny Health System. All operations were performed by three experienced laparoscopic surgeons (R.J.K., R.J.L., and R.H.M.). Follow-up data (office visits and phone interviews) were available for $92 \%$ of the patients. The mean follow-up time was 23.4 months. Thirty-nine of the 612 patients $(6.4 \%)$ required revision of their initial fundoplication. During the same period, 15 patients who had been operated on at other institutions were referred to our practice for failure of their primary repair (Figure 1). Previous operations included laparoscopic Nissen fundoplication $(n=42)$, laparoscopic Toupet fundoplication $(n=4)$, open Nissen fundoplication $(n=7)$, and Belsey Mark IV fundoplication $(n=1)$. Seven of the 15 referred patients had undergone an open fundoplication. We conducted a retrospective analysis to determine the primary symptom that led to reoperation, the reason for failure of the initial surgery, the success of reoperation in alleviating GERD symptoms, and the postoperative need for antireflux medications.

Workup before reoperative fundoplication included esophagogastroduodenoscopy (EGD) and barium esophagogram in all cases. Esophageal manometry was performed in 34 of 54 cases (63\%), and 24-hour esophageal $\mathrm{pH}$ monitoring was done in 32 of 54 cases $(59 \%)$. The remaining patients either refused or could not tolerate the studies. A nuclear motility study was ordered for 5 of those patients. Another 5 patients underwent nuclear gastric emptying studies to rule out gastroparesis. Patients with impaired esophageal peristalsis were offered a partial fundoplication.

Patients were offered reoperative repair if they had evidence of anatomic failure of the fundoplication that correlated with their symptoms. Patients with normal configuration of the fundoplication but with evidence of esophagitis on EGD or abnormal 24-hour $\mathrm{pH}$ study were offered surgery if they medical treatment of their GERD symptoms failed. All patients undergoing reoperation underwent a laparoscopic approach, regardless of the approach used in the initial surgery. The technique we used to perform laparoscopic complete or partial fundoplication has been previously described in detail elsewhere. ${ }^{18}$ All fundoplications were taken down and dissected free of the surrounding tissues. The short gastric vessels were routinely divided if this had not been done at the original surgery. Mediastinal dissection of the esophagus was performed in order to mobilize at least $3 \mathrm{~cm}$ of intra-abdominal esophagus. The hiatus was closed posterior to the esophagus with interrupted, nonabsorbable sutures. The fundic wrap was then recreated as either a floppy complete fundoplication (Nissen) or as a posterior $270^{\circ}$ fundoplication (Toupet) around a $56 \mathrm{~F}$ to $60 \mathrm{~F}$ bougie. The wrap was secured to the hiatus with nonabsorbable sutures.

Symptoms such as heartburn, dysphagia, and gas bloat were evaluated before and after reoperation with the application of a visual analog scoring scale from 0 to 10 in severity: 0 , no symptoms, to 10 , severe symptoms. Sense of well-being ( 0 , poor, to 10 , 
TABLE 1. Type of reoperative antireflux procedure

\begin{tabular}{lrcccc}
\hline & \multicolumn{4}{c}{ Initial surgery } & \\
\cline { 2 - 4 } Reoperative surgery & Nissen & Toupet & Belsey Mark IV & Total \\
\hline Nissen fundoplication & 22 & 4 & 1 & $27(50 \%)$ \\
Toupet fundoplication & 24 & 0 & 0 & $24(44 \%)$ \\
Dor fundoplication & 2 & 0 & 0 & $2(4 \%)$ \\
Heller myotomy/Toupet & 1 & 0 & 0 & $1(2 \%)$ \\
\hline
\end{tabular}

great) and level of activity ( 0 , sedentary, to 10 , very active) were assessed with similar 10-point scales. We are currently conducting a prospective study to validate these scoring scales. Fifty of 54 patients $(93 \%)$ had complete preoperative and postoperative questionnaires. The mean patient follow-up time was 22.5 months (range 0.8-57.2 months). Only 7 patients had follow-up less than 6 months. Patients were evaluated with symptom scores before the operation and at each postoperative visit. Symptom scores from the latest follow-up visit were considered for each patient.

A 2-tailed paired Student $t$ test was used for comparison of preoperative and postoperative scores. A Fisher exact test was used for differences in proportions (InStat version 3.01; GraphPad Software, Inc, San Diego, Calif).

\section{Results}

A total of 54 patients underwent laparoscopic attempted reoperation for failed fundoplication. Mean patient age was 47.1 years (range $24-80$ years). The male to female ratio was 1:1.3. Median time from the initial to the repeat procedure was 12.5 months (range 2-185 months, mean 26.9 months). Thirty-three patients $(61 \%)$ underwent reoperative fundoplication within a year from the initial fundoplications, and $46(85 \%)$ did so within 2 years. The primary symptoms prompting operation were heartburn in 26 cases (48\%), dysphagia in 23 cases $(43 \%)$, and gas bloat in 5 cases $(9 \%)$.

Twenty-three patients $(43 \%)$ underwent one or more esophageal dilations for dysphagia (mean 1.5, range 1-5). Preoperative barium esophagram revealed free reflux of contrast $(\mathrm{n}=22)$, deformity of fundoplication $(\mathrm{n}=21)$, tight fundoplication $(\mathrm{n}=7)$, possible achalasia $(\mathrm{n}=1)$, and no abnormal findings $(\mathrm{n}=12)$. Preoperative EGD revealed esophagitis $(n=17)$, Barrett esophagus $(n=9)$, hiatal hernia $(\mathrm{n}=17)$, deformity of fundic wrap $(\mathrm{n}=7)$, tight fundoplication $(n=7)$, and no abnormal findings $(n=17)$. Seventeen of the 34 patients who underwent manometric evaluation had poor esophageal motility diagnosed. Fifteen of the 32 patients who underwent evaluation with 24-hour pH study had an abnormal DeMeester score.

The type of reoperative fundoplication in relation to the initial operation is depicted in Table 1. Three of 54 patients (5.6\%) had conversion to open procedures because of extensive scarring around the gastroesophageal junction. All 3 patients had initially undergone open procedures. Five pa-
TABLE 2. Intraoperative anatomic findings

\begin{tabular}{lrr}
\hline & No. & $\%$ \\
\hline Slipped/misplaced fundoplication & 14 & 26 \\
Disrupted fundoplication & 8 & 15 \\
Transdiaphragmatic herniation of & 7 & 13 \\
$\quad$ fundoplication & & \\
Fundoplication too tight* & 7 & 13 \\
Achalasia & 1 & 2 \\
No finding & 17 & 31 \\
\hline
\end{tabular}

${ }^{*}$ All confirmed radiologically.

\section{TABLE 3. Perioperative complications}

\begin{tabular}{lc}
\hline Complication & No. \\
\hline Intraoperative gastric lacerations & 7 \\
Unrecognized esophageal injury & 1 \\
Persistent nausea & 2 \\
Persistent dysphagia requiring dilation & 1 \\
Significant subcutaneous emphysema & 1 \\
Urinary retention & 1 \\
Postoperative diarrhea & 2
\end{tabular}

tients who had undergone an open primary operation were able to have laparoscopic reoperations. The mean operative time for reoperation was $180 \pm 22$ minutes (range 60-355 minutes). The average hospital stay was $2.3 \pm 1.6$ days (range 1-8 days).

Patients were carefully assessed at the time of operation for the cause of the fundoplication failure. A slipped or misplaced fundoplication was found in $26 \%$ of patients, followed in frequency by a disrupted fundoplication (15\%) and a transdiaphragmatic herniation of the fundoplication (13\%; Table 2). Half of the patients with a slipped or misplaced fundoplication were patients referred to us from other institutions. Seventeen of the 54 patients (31\%) had no obvious reasons for failure noted at the time of reoperation; 8 of 17 patients with recalcitrant dysphagia or gas bloat underwent conversion of a complete fundoplication to a partial fundoplication, and 9 of 17 patients with recalcitrant heartburn documented by 24-hour pH study or EGD underwent repeat fundoplication (Nissen to reoperative Nissen $n$ $=4$, Toupet to Nissen $\mathrm{n}=3$, and Nissen to Toupet $\mathrm{n}=2$, these patients were found to have a loose fundoplication and underwent a partial wrap because of preoperative abnormal esophageal motility).

There were no perioperative deaths in our series. Fourteen patients (18\%) had 15 perioperative complications (Table 3). Seven patients had a laceration of the gastric fundus during dissection of the old fundoplication. The injury was recognized in all cases and repaired intraoperatively with suturing or application of an endoscopic stapling device. One patient with unrecognized esophageal injury had a contained leak that was treated conservatively. An 


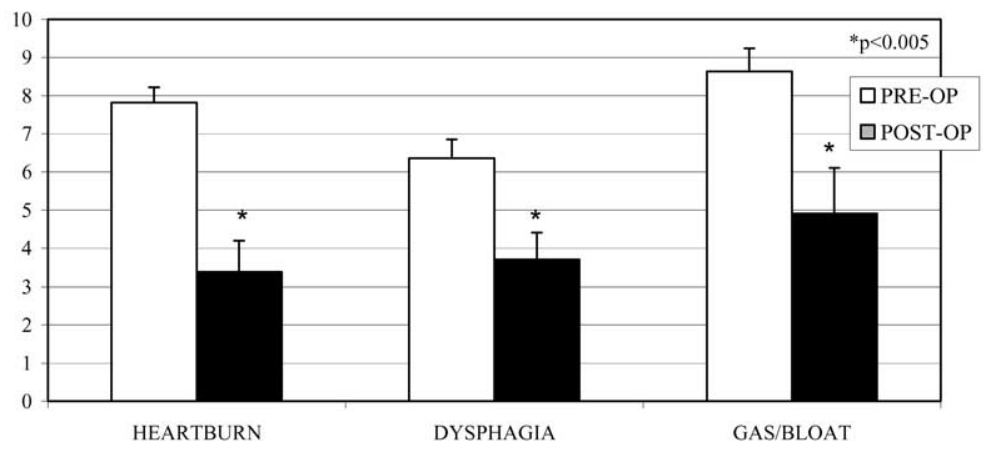

Mean values $\pm \mathrm{SEM}$

Figure 2. Changes in symptom visual analog scores after reoperative fundoplication.

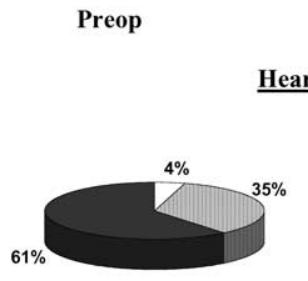

Heartburn

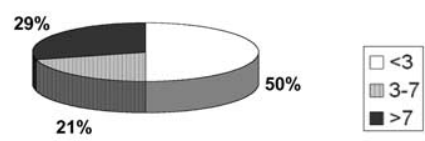

Dysphagia
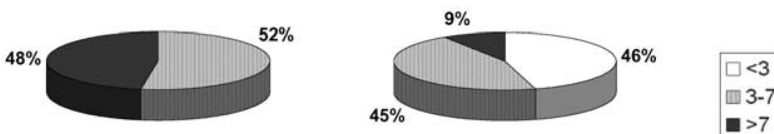

Gas Bloat
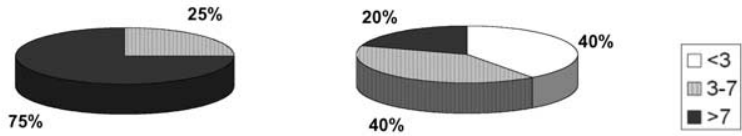

Figure 3. Symptomatic outcomes after reoperative fundoplication.

esophageal swallow study on postoperative day 7 revealed resolution of the leak, and the patient was discharged without further complications.

Three patients $(5.6 \%)$ had failure of the reoperation and eventually underwent subsequent operations. One patient with two previous failed Nissen fundoplications ultimately underwent a Collis gastroplasty for esophageal lengthening to address short esophagus. Another patient with morbid obesity and steroid-dependent asthma related to GERD had undergone two fundoplications without resolution of her symptoms and ultimately required a Roux-en-Y gastric bypass procedure. The third patient had undergone a Belsey
Mark IV and two failed laparoscopic Nissen fundoplications. This patient reported persistent dysphagia, and esophageal manometry revealed aperistalsis of the entire esophagus. The patient underwent a transhiatal esophagectomy for end-stage reflux disease. All 3 patients are now free of reflux symptoms after their final procedure.

Reoperative fundoplication was successful in alleviating the primary complaint in most cases. Postoperative mean visual analog scores decreased significantly for heartburn (from 7.8 to $3.4, P<.0001$ ), dysphagia (from 6.4 to $3.7 ; P$ $<.005$ ), and gas bloat (from 8.6 to $4.9 ; P<.005$; Figure 2). Eighty-two percent of our patients had some improvement in the visual analog score of the primary symptom that led to reoperation. A significant percentage of patients $(40 \%$ $50 \%$ ) had resolution of the primary symptom (score $<3$ ), and a large percentage of patients $(21 \%-45 \%)$ had only moderate postoperative symptoms (score 3-7; Figure 3). Among the 17 patients without identifiable intraoperative reason for the failure of the fundoplication, 12 patients had improvement in the visual analog score of the primary symptom. Quality of life scores increased from 5.5 to $7.2(P$ $<.001)$ after surgery, and activity scores increased from 6.7 to $7.8(P<.01)$. For further assessment of patient satisfaction, patients were asked whether they would make the same decision and undergo a reoperative fundoplication; $70 \%$ of patients replied that they would.

Data regarding preoperative and postoperative medication use was available in 33 of 54 cases (Figure 4). Seventeen of 33 patients $(52 \%)$ were free of any medical treatment for GERD (antacids, histamine blockers, and protonpump inhibitors) after a mean follow-up of 26 months. The reasons for GERD medication use in the remaining 16 patients were peptic ulcer disease $(\mathrm{n}=2)$, dyspepsia $(\mathrm{n}=$ $1)$, and heartburn $(\mathrm{n}=13)$.

\section{Discussion}

The laparoscopic technique has repopularized antireflux surgery and has led to an exponential increase in the number 
of fundoplications performed in the United States. Critics of antireflux surgery claim that it trades one set of symptoms for another, such as dysphagia and gas bloat. Proper patient selection and meticulous surgical technique at the time of the initial operation are among the most important factors in preventing fundoplication failure. Reoperative antireflux surgery, although not as effective as the initial operation, has had acceptable results in alleviating symptoms of heartburn, dysphagia, and gas bloat. Eighty-two percent of our patients had some improvement in the visual analog score of the primary symptom that led to reoperation, and $40 \%$ to $50 \%$ of patients had resolution of their symptoms (score $<3$ ). Hunter and colleagues ${ }^{9}$ reported a $70 \%$ to $91 \%$ improvement in reflux symptoms after reoperative fundoplication. Only 3 of our patients (5.6\%) required any further surgery, compared with the $3.5 \%$ to $13 \%$ failure rate reported in other series. ${ }^{8,9}$ Granderath and associates ${ }^{19}$ reported significantly improved gastrointestinal quality of life scores after reoperative fundoplication surgery. Quality of life and activity scores increased significantly after surgery in our patients. Half of our patients were completely free of the need for any antireflux medications.

Laparoscopic reoperative fundoplication is associated with significant intraoperative complications even when performed by experienced surgeons. ${ }^{20,21}$ Eight of our patients had a gastric or esophageal laceration occur during dissection of the fundoplication. Most of these injuries were readily recognized and repaired without further sequelae. There were no perioperative deaths.

Patients undergoing reoperation require a careful preoperative diagnostic evaluation. A barium swallow study should be the first study ordered for patients with recurrent GERD symptoms or persistent dysphagia after a fundoplication. EGD can be complementary to the swallow study in identifying anatomic reasons for a failed fundoplication. ${ }^{9,22}$ An attempt to obtain 24-hour $\mathrm{pH}$ study and esophageal manometry should be made in every case under consideration for reoperative fundoplication. The 24-hour $\mathrm{pH}$ study is essential in documenting the presence of severe reflux, especially when there is no evidence of anatomic failure of the wrap on the barium esophagram and EGD. Esophageal manometry detected achalasia in 1 of our referred patients, and he was successfully treated with a myotomy. Esophageal manometry is also essential in patients with persistent dysphagia before converting a full fundoplication to a partial one.

An anatomic reason for failure was found in $69 \%$ of our reoperative cases. Properly selected patients without identifiable anatomically distorted fundoplication may also benefit from refundoplication. The mechanisms of anatomic failure in our patients were equally distributed between slipped or misplaced fundoplication, disrupted fundoplication, and transdiaphragmatic herniation. Among patients

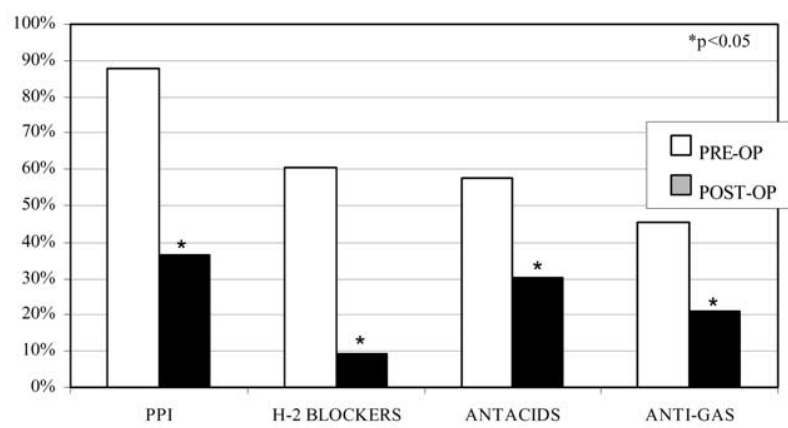

Figure 4. Postoperative antireflux medication use. PPI, Protonpump inhibitors; $H-2$, histamine.

referred from other institutions, the most common mechanism was slipped or misplaced fundoplication. Other studies have shown that in the era of laparoscopic fundoplication, the most common mechanism of failure is transdiaphragmatic herniation of the fundoplication. ${ }^{9,13,23}$ After antireflux surgery, adhesions usually form between the fundoplication and the anterior surface of the liver. The posterior aspect of the fundoplication, however, is relatively free of adhesions, providing access for wrap migration into the chest. ${ }^{9,13,24}$ Inadequate closure of the diaphragmatic crura, shortened esophagus, and poor esophageal mobilization have been implicated as possible mechanisms of fundoplication failure. $^{13,23}$ Soper and coworkers ${ }^{13}$ noted a 5 -fold increase in the anatomic failure rate when complete mobilization of the fundus or routine closure of the diaphragmatic hiatus was not performed.

Pressure at the hiatus from physiologic forces, so-called diaphragmatic stressors, can cause thoracic migration of the fundoplication with or without wrap disruption. ${ }^{9,13}$ Patients who have postoperative retching and report new-onset epigastric or substernal pain should undergo early radiographic evaluation of the fundoplication. It is easier to repair a transdiaphragmatic herniation of the fundoplication in the early postoperative period. We routinely use antiemetic medications during the early postoperative period, and this may explain the absence of immediate postoperative fundoplication failures in our series.

None of our patients required a gastroplasty during the first reoperative fundoplication. However, 1 patient did eventually require a gastroplasty, and that patient might have benefited from an esophageal lengthening procedure at the time of the first reoperation. The decision whether a gastroplasty is necessary is based on our ability to mobilize at least $3 \mathrm{~cm}$ of intra-abdominal esophagus. In our experience, the need for a gastroplasty is very uncommon, but this remains a controversial topic in the surgical literature. ${ }^{25-29}$

The incidence of persistent dysphagia after laparoscopic Nissen fundoplication ranges from $0 \%$ to $36 \%{ }^{30-37}$ Persistent postoperative dysphagia may be related to the length 
and tightness of the fundoplication or to the function of the esophageal body. Bais and associates ${ }^{38}$ reported that conversion of a $360^{\circ}$ into a $270^{\circ}$ wrap resulted in normalization of the lower esophageal sphincter relaxation and a decrease in residual relaxation pressure of the sphincter. Seventy-two percent of our patients had at least a 50\% improvement in their dysphagia scores after conversion from a Nissen to a Toupet fundoplication.

It has been postulated that patients with severe GERD use aerophagia in an attempt to neutralize the acidic environment of the esophagus. ${ }^{39}$ If this habit continues after the operation, patients may have abdominal bloating and excessive flatulence. The reduced ability to belch after a fundoplication contributes to this malady. Treatment with gasbinding agents and prokinetics, along with avoidance of carbonated beverages, may help to alleviate symptoms of gas bloat. There is much variation in the reported incidences of gas bloat after fundoplication; $1.5 \%$ to $100 \%$ of patients are unable to belch, $31 \%$ to $63 \%$ are unable to vomit, and $13 \%$ to $67 \%$ report gas bloat. ${ }^{40}$ It is unknown why patients respond to reoperation for symptoms of gas bloat. A tight or improperly positioned fundoplication may create an inability to expel swallowed air. Revision of the fundoplication in the 5 patients who reported severe gas bloat resulted in resolution of symptoms in 2 cases and improvement of symptoms in 2 cases.

\section{Conclusion}

Laparoscopic reoperation is a feasible and relatively safe option for the treatment of failed fundoplication. Symptomatic relief is achieved in a large percentage of patients; however, patient satisfaction is much lower than with a primarily successful fundoplication. Prevention of fundoplication failure with proper patient selection and surgical technique should be the goal in achieving the best results.

\section{References}

1. Princeton N. A Gallup survey on heartburn across America. Washington, DC: The Gallup Organization; 1988.

2. Nebel OT, Fornes MF, Castell DO. Symptomatic gastroesophageal reflux: incidence and precipitating factors. Am J Dig Dis. 1976;21: 953-6.

3. Hinder RA, Libbey JS, Gorecki P, Bammer T. Antireflux surgery. Indications, preoperative evaluation, and outcome. Gastroenterol Clin North Am. 1999;28:987-1005, viii.

4. DeMeester TR, Fuchs KH. Preoperative evaluation of gastroesophageal reflux. Curr Ther Cardiothorac Surg. 1989:217-20.

5. Hetzel DJ, Dent J, Reed WD, Narielvala FM, Mackinnon M, McCarthy JH, et al. Healing and relapse of severe peptic esophagitis after treatment with omeprazole. Gastroenterology. 1988;95:903-12.

6. Liu JY, Woloshin S, Laycock WS, Schwartz LM. Late outcomes after laparoscopic surgery for gastroesophageal reflux. Arch Surg. 2002; 137:397-401.

7. DeMeester TR, Bonavina L, Albertucci M. Nissen fundoplication for gastroesophageal reflux disease. Evaluation of primary repair in 100 consecutive patients. Ann Surg. 1986;204:9-20.

8. Lafullarde T, Watson DI, Jamieson GG, Myers JC, Game PA, Devitt
PG. Laparoscopic Nissen fundoplication: five-year results and beyond. Arch Surg. 2001;136:180-4.

9. Hunter JG, Smith CD, Branum GD, Waring JP, Trus TL, Cornwell M, et al. Laparoscopic fundoplication failures: patterns of failure and response to fundoplication revision. Ann Surg. 1999;230:595-606.

10. Anvari M, Allen C. Five-year comprehensive outcomes evaluation in 181 patients after laparoscopic Nissen fundoplication. J Am Coll Surg. 2003;196:51-9.

11. Hinder RA, Filipi CJ, Wetscher G, Neary P, DeMeester TR, Perdikis G. Laparoscopic Nissen fundoplication is an effective treatment for gastroesophageal reflux disease. Ann Surg. 1994;220:472-83.

12. Hunter JG, Trus TL, Branum GD, Waring JP, Wood WC. A physiologic approach to laparoscopic fundoplication for gastroesophageal reflux disease. Ann Surg. 1996;223:673-87.

13. Soper NJ, Dunnegan D. Anatomic fundoplication failure after laparoscopic antireflux surgery. Ann Surg. 1999;229:669-77.

14. DePaula AL, Hashiba K, Bafutto M, Machado CA. Laparoscopic reoperations after failed and complicated antireflux operations. Surg Endosc. 1995;9:681-6.

15. Rieger NA, Jamieson GG, Britten-Jones R, Tew S. Reoperation after failed antireflux surgery. Br J Surg. 1994;81:1159-61.

16. Szwerc MF, Wiechmann RJ, Maley RH, Santucci TS, Macherey RS, Landreneau RJ. Reoperative laparoscopic antireflux surgery. Surgery. 1999;126:723-9.

17. Stein HJ, Feussner H, Siewert JR. Failure of antireflux surgery: causes and management strategies. Am J Surg. 1996;171:36-40.

18. Landreneau RJ, Keenan RJ, Ferson PF. Gastroesophageal reflux disease. In: Cameron JL, editor. Current surgical therapy. Philadelphia: Mosby; 1995. p. 25-33.

19. Granderath FA, Kamolz T, Schweiger UM, Pasiut M, Haas CF, Wykypiel $\mathrm{H}$, et al. Is laparoscopic refundoplication feasible in patients with failed primary open antireflux surgery? Surg Endosc. 2002;16: 381-5.

20. Curet MJ, Josloff RK, Schoeb O, Zucker KA. Laparoscopic reoperation for failed antireflux procedures. Arch Surg. 1999;134:559-63.

21. Serafini FM, Bloomston M, Zervos E, Muench J, Albrink MH, Murr $\mathrm{M}$, et al. Laparoscopic revision of failed antireflux operations. $J$ Surg Res. 2001;95:13-8.

22. Jailwala J, Massey B, Staff D, Shaker R, Hogan W. Post-fundoplication symptoms: the role for endoscopic assessment of fundoplication integrity. Gastrointest Endosc. 2001;54:351-6.

23. Horgan S, Pohl D, Bogetti D, Eubanks T, Pellegrini C. Failed antireflux surgery: what have we learned from reoperations? Arch Surg. 1999;134:809-17.

24. Watson DI, Jamieson GG, Devitt PG, Mitchell PC, Game PA. Paraoesophageal hiatus hernia: an important complication of laparoscopic Nissen fundoplication. Br J Surg. 1995;82:521-3.

25. Jobe BA, Horvath KD, Swanstrom LL. Postoperative function following laparoscopic Collis gastroplasty for shortened esophagus. Arch Surg. 1998;133:867-74.

26. Johnson AB, Oddsdottir M, Hunter JG. Laparoscopic Collis gastroplasty and Nissen fundoplication. A new technique for the management of esophageal foreshortening. Surg Endosc. 1998;12:1055-60.

27. Gastal OL, Hagen JA, Peters JH, Campos GM, Hashemi M, Theisen J, et al. Short esophagus: analysis of predictors and clinical implications. Arch Surg. 1999;134:633-68.

28. Korn O, Csendes A, Burdiles P, Braghetto I, Sagastume H, Biagini L. Length of the esophagus in patients with gastroesophageal reflux disease and Barrett's esophagus compared to controls. Surgery. 2003; 133:358-63.

29. DeMeester SR, DeMeester TR. Editorial comment: the short esophagus: going, going, gone? Surgery. 2003;133:364-7.

30. Herron DM, Swanstrom LL, Ramzi N, Hansen PD. Factors predictive of dysphagia after laparoscopic Nissen fundoplication. Surg Endosc. 1999;13:1180-3.

31. Dallemagne B, Weerts JM, Jeahes C, Markiewicz S. Results of laparoscopic Nissen fundoplication. Hepatogastroenterology. 1998;45:1338-43.

32. Perdikis G, Hinder RA, Lund RJ, Raiser F, Katada N. Laparoscopic Nissen fundoplication: where do we stand? Surg Laparosc Endosc. 1997; 7:17-21. 
33. O'Reilly MJ, Mullins SG, Saye WB, Pinto SE, Falkner PT. Laparoscopic posterior partial fundoplication: analysis of 100 consecutive cases. J Laparoendosc Surg. 1996;6:141-50.

34. Anvari M, Allen C. Esophageal and lower esophageal sphincter pressure profiles 6 and 24 months after laparoscopic fundoplication and their association with postoperative dysphagia. Surg Endosc. 1998;12:421-6.

35. Patti MG, De Pinto M, de Bellis M, Arcerito M, Tong J, Wang A, et al. Comparison of laparoscopic total and partial fundoplication for gastroesophageal reflux. J Gastrointest Surg. 1997;1:309-15.

36. Rydberg L, Ruth M, Abrahamsson H, Lundell L. Tailoring antireflux surgery: a randomized clinical trial. World J Surg. 1999;23:612-8.

37. Gotley DC, Smithers BM, Rhodes M, Menzies B, Branicki FJ, Nathanson L. Laparoscopic Nissen fundoplication-200 consecutive cases. Gut. 1996;38:487-91.

38. Bais JE, Wijnhoven BP, Masclee AA, Smout AJ, Gooszen HG. Analysis and surgical treatment of persistent dysphagia after Nissen fundoplication. Br J Surg. 2001;88:569-76.

39. Katzka D, DiMarion A Jr. Pathophysiology of gastroesophageal reflux disease: LES incompetence and esophageal clearance. In: Castell DO, editor. The esophagus. Boston: Little, Brown; 1992. p. 449-55.

40. Tew S, Ackroyd R, Jamieson GG, Holloway RH. Belching and bloating: facts and fantasy after antireflux surgery. Br J Surg. 2000;87:47781.

\section{Discussion}

Dr Claude Deschamps (Rochester, Minn). Papasavas and coauthors have reported on a group of 54 patients who underwent reoperation laparoscopically for a variety of reasons. Postoperative symptoms and quality of life and activity scores as assessed by the patients themselves were improved in most cases, and the need for medication also decreased significantly. The group should be commended for their low morbidity and good subjective results in the face of a challenge that can be sometimes frustrating for the gastroenterologist and the surgeon.

I would like to point out a couple limitations. First, we know from Tom DeMeester's group and others that there is often discrepancy between the subjectivity of postfundoplication symptoms and the results of objective testing, such as 24-hour $\mathrm{pH}$. Papasavas and coauthors evaluated their patients very carefully before the operation. They used $\mathrm{pH}$, manometry, and barium swallow. However, they did not use such objective measures in their postoperative evaluation. It would have been nice to have some measurement, such as a postoperative barium swallow.

Second, the conclusions are based on a mean follow-up of 22 months. We and others have shown that reoperative results are not as good as those of first operations and often deteriorate with time. There is a risk of minimizing the consequences of a reoperative laparoscopic approach in projecting these good early results into the future. As the number of laparoscopic fundoplications has increased exponentially nationwide, our esophageal clinic has been filling up with patients who report postfundoplication symptoms. Some of these patients have not been helped by a reoperation, and the term "esophageal cripple" comes to mind when you see a patient who has undergone four laparoscopic repairs and, incredibly and sadly, is asking for a fifth.

I have four questions for Dr Keenan. (1) Do you do all reoperations laparoscopically? Do you use some selection criteria? At my institution, we don't routinely do reoperations laparoscopically. (2) It is not clear how many patients in your group were undergoing second or third reoperations. Were such cases excluded, or does your group do these open only? (3) What is your current practice in terms of following up patients, and with what type of test do you follow up, if you use any objective testing? (4) Finally, there were no gastroplasties in your group, and I do think that there should have been some. Please comment.

Dr Keenan. Thank you, Dr Deschamps, for your always insightful comments.

The reoperations were all attempted laparoscopically. That is our standard approach, to attempt to repair laparoscopically. If there is some intraoperative reason to convert to an open procedure, then we do so.

All 54 patients I talked about in this series were undergoing their second operation. Three of those 54 subsequently went on to a third procedure because of failure of the reoperation.

Our follow-up is performed at regular intervals, as I mentioned, with questionnaires at every visit, and we also do barium swallow and motility and 24-hour $\mathrm{pH}$ studies. If we are unable or the patient refuses, then we attempt to get nuclear transit studies at 6 months after the operation and then at 1 year, and then yearly thereafter, if they will agree to that.

I did not include the more objective indicators of success in the presentation because I was primarily interested in symptomatic improvement. That is the reason that these patients underwent a second operation. Of course, without evidence to prove that they had some objective reason for having the second operation, they would not have undergone it.

And you are right, none of the patients did have a gastroplasty at the second operation. What we do is take down the wrap, remobilize the esophagus and make sure that it's completely mobilized, and then redo the wrap. Probably there are a few cases in which we should have done a Collis gastroplasty, including the 1 patient who subsequently had a gastroplasty at the third operation, but we believe that the need for a gastroplasty is not all that common. So unless we see true evidence of esophageal shortening after full mobilization and taking down of the wrap, I think that it's not necessary.

Dr James D. Luketich (Pittsburgh, $\mathrm{Pa}$ ). We're interested in the symptom scores as well, some of the issues you mentioned about heartburn, dysphagia, and so on. Where did you obtain the questionnaire form? Is this a validated form in other studies? Did you consider using another standard form of outcome study for reflux? For example, the health-related quality of life has been validated by Velanovich and many others. What made you choose this particular scoring system?

Second, I think you mentioned a number of patients, and I don't remember the exact number, maybe 9 , in whom at exploration you did not find an anatomic defect. What did you do in those cases? Can you explain how some of them might have gotten better after surgery, because I think some of those did improve? Do you think you just didn't quite figure it out, but the wrap seemed to work the second time? Did any of those just happen to be related to vagal injuries, or did you document that? Did you have trouble in your reoperation group with vagal injuries? We've seen some of those, and I know it can be very difficult to identify and avoid it on the second operation.

Dr Keenan. You're right, and obviously we've all dealt with these kinds of difficult issues. The analog score that we were using has been used at our institution and other institutions for these symptoms for several years and obviously is an adaptable scoring system for a number of different indications. We had not early on 
been using a much more objective study as you have been doing, and we have started doing that in the last couple of years, really a year and a half, and so I don't have enough information to really tell you on that topic.

With respect to the anatomic defects, I think that some of those were probably patients in whom there was some mild distortion of the wrap that maybe we could have seen if we had looked at the barium swallow or a video of the barium swallow rather than just the static pictures. I think that we certainly tend to tack the wrap up to the diaphragm to the crura, to try to prevent that iatrogenic paraesophageal herniation. Maybe were twisting it a little bit and that was all we found, and yet it wasn't really obvious at the time of surgery.

And you are right, vagal nerve innervation and injury is a very critical issue, and we certainly do our best. I'm not sure how many we might have injured, but I am certain that we make a very strong effort to identify at least one of the vagal nerves and do everything we can to protect it if we can't see both.

Dr William H. Warren (Chicago, Ill). I'm somewhat confused as to the choice of operation and what factors went into making that choice. Can you elaborate on that, preoperative motility or intraoperative findings?
Dr Keenan. I should have been more clear about that, and I appreciate the question. The conversion from a complete Nissen to a partial Nissen was done for essentially all patients who reported postoperative dysphagia or persistent dysphagia. The 25 patients in whom heartburn was the problem either had a reoperative Nissen fundoplication, if the original had been a Nissen and we found one of those anatomic defects, or, if the original had been a partial fundoplication, conversion to a complete fundoplication for heartburn.

Dr Stephen R. Hazelrigg (Springfield, Ill). When we've analyzed our failures from Nissens, especially the ones that have symptomatic failures without anatomic defects, we found when we go back and look at their preoperative questionnaire that they also had a lot of other more lower gastrointestinal complaints, such as irritable bowel. Did you have any similar findings in your group?

Dr Keenan. Absolutely. In fact, that is a topic that is currently being looked at by one of our fellows right now. I think there is a tremendous association between reflux disease and irritable bowel syndrome, and I think that the patients with irritable bowel are a much more difficult subgroup to deal with and have a lot more subjective postoperative symptoms. In many of those situations, you can't find any objective data to support their subjective difficulties.

\section{JTCVS On-Line Manuscript Submission and Review}

\section{Please visit http://www.editorialmanager.com/jtcvs/}

Effective September 15, 2001, authors and reviewers may submit manuscripts and reviews electronically via Editorial Manager, our new Web-based system with full electronic submission, review, and status update capabilities.

As we move from paper to electronic submissions, the Editorial Office will make proxy submissions of all manuscripts accompanied by a diskette containing the electronic files of the text, tables, and figures. Editors, authors, and reviewers will receive automatic e-mails when significant events occur.

We strongly encourage all authors and reviewers to use Editorial Manager. Although we will continue to accommodate the submission of paper manuscripts for some months, our goal is to be completely electronic within 9 to 12 months.

All individuals currently in our database for whom we have e-mail addresses will receive via e-mail a system-assigned username and password that can be used to log in to the system without prior registration. All those not receiving the e-mail must register the first time they use the system.

As with any broad systemic change, the conversion to the new system will take some time to complete. We ask your patience as we replace our in-office database with the new system. We also encourage you to take advantage of the speed and efficiency that the new system will provide for us all: editor, author, reviewer, and publisher. 